\title{
IMAGEAMENTO ELÉTRICO COMO FERRAMENTA DE MONITORAMENTO DO COMPORTAMENTO DA ÁGUA NO SOLO
}

\author{
Andréia de Almeida ${ }^{1}$; Bruno E. Távora ${ }^{2}$; Tiago B. Kisaka ${ }^{3}$; Gilliard Nunes Silva ${ }^{4}$; Carlos T.C. \\ Nascimento $^{5}$; Sérgio Koide ${ }^{6}$
}

\begin{abstract}
Resumo - Zonas ripárias favorecem a conectividade hidrológica entre a vertente e os corpos hídricos, sendo essencial a compreensão dos processos hidrológicos que se nelas se estabelecem. O entendimento desses processos requer informações a respeito de umidade do solo e das flutuações do nível da água subterrânea. Com isso, este trabalho consistiu na aquisição de dados geofísicos em ambiente de zona ripária com o objetivo de caracterização do comportamento da água no solo. A bacia do córrego Capetinga, localizada na porção sul do Distrito Federal, foi selecionada para realização dos levantamentos geofísicos no período de agosto de 2015 a fevereiro de 2016. Aplicouse o método elétrico de corrente contínua para aquisição de dados de resistividade elétrica, com a técnica de caminhamento elétrico e arranjo de Wenner, em três linhas de monitoramento $(A, B$ e $C)$. Valores de resistividade abaixo de $3000 \Omega . m$ foram considerados como indicativo da zona saturada do solo. Nas seções $B$ e $C$ houve comportamento geoelétrico estratificado, com redução gradual da resistividade nas camadas profundas. A variação temporal dos valores de resistividade também foi identificada. O método demonstrou-se adequado ao objetivo estabelecido, permitindo obter informações qualitativas do comportamento da água no solo em zonas ripárias.
\end{abstract}

Abstract - Riparian zones favor the hydrological connectivity between the hillslope and streams, it is essential to understanding the hydrological processes that are established in them. Understanding these processes requires information about soil moisture and fluctuations in the groundwater level. Thus, this work consisted of the acquisition of geophysical data in riparian zone in order to characterize the behavior of water in the soil. The watershed of the Capetinga stream, located in the southern part of the District Federal, was selected to carry out the geophysical surveys from August 2015 to February 2016. We used the electric method of direct current for the acquisition of electrical resistivity data, the electrical profiling technique and Wenner arrangement in three rows

\footnotetext{
${ }^{1}$ Universidade de Brasília, Campus Darcy Ribeiro, Asa Norte - DF, 70910-900, (61) 3107-0944, dealmeida15@ gmail.com

${ }^{2}$ Universidade de Brasília, Campus Darcy Ribeiro, Asa Norte - DF, 70910-900, (61) 3107-0944, bruno.eng.ambiental@ gmail.com

${ }^{3}$ Universidade de Brasília, Campus Darcy Ribeiro, Asa Norte - DF, 70910-900, (61) 3107-0944, tiagobk.df@ gmail.com

${ }^{4}$ Universidade de Brasília, Campus Darcy Ribeiro, Asa Norte - DF, 70910-900, (61) 3107-0944, nunes.ba70@ gmail.com

${ }^{5}$ Universidade de Brasília, Campus Planaltina, Planaltina - DF, 73345-010, (61) 3107-8052, carlostadeu@unb.br

${ }^{6}$ Universidade de Brasília, Campus Darcy Ribeiro, Asa Norte - DF, 70910-900, (61) 3107-0926, skoide@ unb.br
} 
monitoring ( $A, B$ and $C$ ). Resistivity values below $3000 \Omega . m$ were considered indicative of the saturated soil zone. In sections $B$ and $C$ were stratified geoelectrical behavior, with gradual reduction of the resistivity in the deep layers. The temporal variation of the resistivity values was also identified. The method was demonstrated adequate to the established goal, allowing obtaining qualitative information water behavior in the soil in riparian zones.

Palavras-Chave - zona ripária, geofísica, caminhamento elétrico vertical.

\section{1 - INTRODUÇÃO}

Zonas ripárias são ecossistemas de interface terrestre e aquático que se caracterizam pela interação entre a vegetação, o solo e os recursos hídricos superficiais e subterrâneos (Lowrance $e t$ al., 1984; Zarroca et al., 2014). A estrutura desses ambientes permite o controle do movimento de massa, do microclima e da diversidade de espécies, bem como provê o serviço ecossistêmico de manutenção dos recursos hídricos (Naiman e Décamps, 1997). Diante disso, a abordagem dos processos hidrológicos que se estabelecem nas zonas ripárias, com especial atenção às águas subterrâneas, favorece a percepção da importância desse ecossistema junto à proteção das águas na escala de bacia hidrográfica, com relevância no contexto da gestão de recursos hídricos (Naiman et al., 2005; Jencso et al.; 2010; Freyberger et al., 2014; Poulsen et al., 2015).

Apesar das lacunas existentes quanto ao funcionamento das zonas ripárias, é sabido que a conectividade hidrológica estabelecida nas vertentes, entre recursos hídricos superficiais e subterrâneos, é essencial para a geração de escoamento e transporte de solutos e nutrientes aos corpos hídricos superficiais (Burt et al., 2002; Jencso et al., 2010). Quanto à geração de escoamento, a conectividade é um elemento chave para se determinar o comportamento das bacias hidrográficas frente aos eventos de precipitação (Detty et al., 2010). Conforme Wienhofer et al. (2009), a relação chuva-vazão em pequenas bacias é controlada principalmente por processos hidrológicos na escala de encosta. Além disso, o escoamento subterrâneo em vertentes é considerado significativo para ambientes lóticos nas regiões de cabeceira por manter a disponibilidade hídrica dos canais adjacentes (Brutsaert, 2005; Blumstock et al., 2015).

No entanto, informações acerca da variação do nível freático, gradiente hidráulico e padrões de fluxo ainda são consideradas escassas (Burt et al., 2002; Castelloé et al., 2015). Como afirmam Monte-Mor et al. (2012), o estudo do comportamento hidrológico de bacias requer redes de monitoramento que demandam investimentos financeiros elevados, principalmente no que diz respeito à medições de conteúdo e pressão da água no solo, escoamento superficial em encostas, 
vazão sólida, precipitação, evaporação e vazão. Nas zonas ripárias esse cenário não se diferencia, especialmente em decorrência do caráter invasivo e dispendioso das abordagens convencionais para aquisição de dados (Musgrave e Binley, 2011). Em alternativa, métodos geofísicos têm sido empregados no estudo do comportamento da água no solo (Andersen et al., 2013; Zarroca et al., 2014; Awan et al., 2015). Os levantamentos geofísicos permitem a determinação indireta da natureza de estruturas subsuperficiais, considerando medições periódicas dos parâmetros de interesse, tanto na superfície terrestre como por meio de poços (Neves e Luiz, 2015). Dentre os métodos geofísicos, o método elétrico de corrente contínua, baseado na medição da resistividade elétrica, permite o monitoramento da umidade do solo e a identificação do nível da água em aquíferos (Fetter, 1994). Esse método representa uma alternativa barata, não invasiva e simples de monitoramento geoelétrico da subsuperfície rasa (Loke, 2001; Ren e Tang, 2014; Yeboah-Forson et al., 2014).

De acordo com Asry et al. (2012), o interesse crescente pelos recursos hídricos subterrâneos ocasionou estudos intensivos a respeito da geometria e das propriedades dos aquíferos, com papel de relevância para aplicação dos métodos geofísicos, especialmente na identificação da profundidade da água subterrânea. Desse modo, o método elétrico de corrente contínua tem se mostrado adequado na identificação e delimitação de plumas de contaminantes (Nascimento et al., 2004; Eunice et al., 2011; Donohue et al., 2015) e estudo do comportamento da água nas zonas não saturada e saturada do solo (Asry, 2012; Calamita et al., 2012; Chukwauma et al., 2015). Além disso, a correlação entre a resistividade elétrica e outras propriedades físicas do solo, tais como condutividade hidráulica e umidade, podem ser observadas nos trabalho de Knight et al. (2010) e Brillante et al. (2014).

Como afirmam Nascimento et al. (2001), esse método responde rapidamente à variações de umidade no solo. Desse modo, por possuir natureza não invasiva, de baixo custo e fornecer medidas sensíveis às características do meio, o método elétrico de corrente contínua permite diagnosticar, de maneira indireta, variações de umidade do solo e do nível do lençol freático (Besson et al. 2010). A resistividade é inversamente proporcional ao volume de água presente no solo ou rocha e ao conteúdo de material em solução na água (Orellana, 1972). No caso dos solos, a dimensão das partículas constituintes também tem influência no valor da resistividade, uma vez que, quanto menor seu tamanho, mais umidade será retida e, portanto os valores de resistividade elétrica serão reduzidos. Além disso, esse parâmetro varia em função da porosidade, textura, saturação e resistividade do fluido contido nos poros do solo (Loke, 2001; Asry et al., 2012).

Desse modo, o presente estudo tem como objetivo analisar o comportamento da água no solo, considerando a variação temporal (agosto de 2015 a fevereiro de 2016) e espacial (no gradiente de declividade da vertente) por meio de levantamentos geofísicos. O método elétrico de 
corrente contínua foi selecionado por demonstrar-se adequado ao objetivo do estudo, a exemplo dos trabalhos desenvolvidos por Asry et al. (2012), Andersen et al. (2013) e Zarroca et al. (2014). A resistividade elétrica foi então monitorada como ferramenta de caracterização da zona ripária quanto ao comportamento da umidade do solo e do nível da água subterrânea, com estudo de caso na vertente do córrego Capetinga, Distrito Federal.

\section{2 - MÉTODO ELÉTRICO DE CORRENTE CONTÍNUA}

O método elétrico de corrente contínua requer a passagem de uma corrente elétrica de intensidade $I$ no solo através de um par de eletrodos fixados à superfície do terreno $(A$ e $B)$. A diferença de potencial $(\Delta \Phi)$ que se forma no solo deve ser medida utilizando um segundo par de eletrodos $(M$ e $N)$. Conhecendo a corrente que percorre o subsolo, a geometria de disposição dos eletrodos e o potencial medido, calcula-se a resistividade elétrica $\left(\rho_{a}\right)$ que, por ser medida em um meio heterogêneo e anisotrópico e ser função do arranjo de eletrodos, é dita aparente (Orellana, 1972; Telford et al., 1985) (Equação 1).

$$
\rho_{a}=K \times \frac{\Delta \Phi}{I}
$$

Os equipamentos utilizados nos levantamentos geofísicos medem, em sua maioria, valores de resistência elétrica $(R)$, cuja unidade é $\operatorname{Ohm}(\Omega)$ e consiste na razão entre a diferença de potencial e a intensidade da corrente, conforme Equação (2). A resistividade elétrica $\left(\rho_{a}\right)$, por sua vez, será definida como o produto entre a resistência $(R)$ à passagem da corrente e o comprimento $(L)$ considerado na direção perpendicular a uma das faces de um volume unitário, resultando numa medida de resistência longitudinal de dado material à passagem da corrente elétrica, expressa em Ohm.m (S.m) (Koefoed, 1979) (Equação 3).

$$
\begin{gathered}
R=\frac{\Delta \Phi}{I} \\
\rho_{a}=L R
\end{gathered}
$$

Além da definição do método geofísico a ser trabalhando, que neste caso restringe-se ao método elétrico de corrente contínua, o levantamento geofísico requer a definição do arranjo e da técnica a serem empregados no trabalho em campo. Os arranjos, isto é, a forma de disposição dos 
eletrodos no terreno, mais comumente utilizados são os de Schlumberger e Wenner. No arranjo de Schlumberger, criado pelo geólogo Conrad Schlumberger e empregado inicialmente em 1912, os eletrodos são distribuídos ao longo de uma linha reta, com distância entre os eletrodos de corrente maior ou igual a três vezes a distância entre os eletrodos de potencial (Koefoed, 1979). O arranjo de Wenner, por sua vez, criado em 1915 pelo físico norte-americano Frank Wenner, considera um espaçamento fixo $(a)$ entre os eletrodos de corrente $(A B)$ e de potencial $(M N)$ (Feitosa, 1997).

No arranjo de Schlumberger a resistividade aparente em um dado ponto do terreno é determinada pela Equação (4), onde $I$ representa a intensidade da corrente em amperes $(A), \Delta \Phi$ diz respeito à diferença de potencial medida no terreno, em volts $(V), A B$ é a distância entre os eletrodos de corrente e $M N$ a distância entre os eletrodos de potencial, ambos em metros ( $m$ ) (Fetter, 1994). Para o arranjo de Wenner, que apresenta três variações, o valor de resistividade aparente é obtido conforme Tabela1 (Carpenter, 1955). Dentre as variações, o arranjo denominado $\alpha$-Wenner, com eletrodos de potencial situados entre os eletrodos de corrente, é utilizado de maneira mais ampla. Existem ainda os arranjos $\beta$-Wenner e $\gamma$-Wenner, nos quais os eletrodos de potencial e de corrente podem ser dispostos aos pares ou lado a lado, respectivamente.

$$
\rho a=\frac{\left(\frac{A B}{2}\right)^{2}-\left(\frac{M N}{2}\right)^{2}}{M N}-\frac{(\pi \times \Delta \Phi)}{I}
$$

Tabela1. Variações do arranjo de Wenner.

\begin{tabular}{cccccc}
\hline Denominação & \multicolumn{4}{l}{ Disposição dos eletrodos } & Resistividade aparente (Ohm.m) \\
\hline$\alpha$-Wenner & $A$ & $M$ & $N$ & $B$ & $\rho \alpha=(2 \times a \times \pi \times \Delta \Phi) / i$ \\
$\beta$-Wenner & $A$ & $B$ & $M$ & $N$ & $\rho \beta=(6 \times a \times \pi \times \Delta \Phi) / i$ \\
$\gamma$-Wenner & $A$ & $M$ & $B$ & $N$ & $\rho \gamma=(3 \times a \times \pi \times \Delta \Phi) / i$ \\
\hline
\end{tabular}

Fonte: Carpenter (1955).

A profundidade de investigação de um arranjo deve ser aquela para a qual a medida de resistividade pode ser melhor atribuída e depende das posições relativas dos quatro eletrodos do arranjo (Barker, 1989). No arranjo de Schlumberger, a profundidade teórica de investigação é determinada entre $A B / 2$ e $A B / 5$. Para o arranjo de Wenner a profundidade de uma dada medida seria aproximadamente metade do espaçamento entre os eletrodos (a/2) (Barker, 1989). Além da determinação do arranjo, o levantamento geofísico requer a seleção da técnica de investigação, que pode assumir as formas de sondagem, caminhamento ou perfilagem (Braga, 2007). A perfilagem elétrica consiste na investigação geoelétrica vertical no interior de furos de sondagem mecânica, 
conforme Braga (2007). No caso da sondagem elétrica vertical (SEV) a investigação é realizada em profundidade a partir de um ponto fixo na superfície do terreno (Braga, 2007). Durante a $S E V$, os eletrodos $M$ e $N$ são mantidos fixos e os eletrodos $A$ e $B$ são deslocados lateralmente. Quanto maior a distância entre $A$ e $B$, maior a profundidade alcançada (Feitosa, 1997).

Por fim, a técnica de caminhamento elétrico $(C E)$, também denominada perfilagem elétrica horizontal, é definida como a investigação lateral a partir de pontos não fixos na superfície do terreno, com uma ou mais profundidades constantes (Braga, 2007). Nessa técnica são efetuadas medições de resistividade aparente ao longo de um perfil, deslocando-se todo o arranjo de eletrodos a cada nova medida (Feitosa, 1997). Em geral o arranjo de Wenner é utilizando para aplicação dessa técnica, permitindo o mapeamento detalhado da resistividade (Asry et al., 2012). De acordo com Wunderlich et al. (2015), apesar da necessidade de instalação de perfis individuais que tornam a aquisição de dados mais demorada, a principal vantagem do caminhamento consiste na ampla distribuição dos dados de resistividade elétrica, com melhor resolução ao longo da profundidade investigada.

Os resultados obtidos por meio do caminhamento elétrico podem ser apresentados por meio de mapas (a uma ou mais profundidades determinadas) e seções ou perfis geoelétricos (com várias profundidades de investigação) (Braga, 2007). Por fim, como ressalta Loke (2001), os dados de resistividade aparente obtidos em campo devem ser submetidos ao processo de inversão para tornarem-se representativos do meio investigado. O objetivo da inversão é estimar parâmetros para elaboração de um modelo que melhor represente o comportamento geoelétrico da subsuperfície a partir de um conjunto de medições discretas em campo (Buettner et al., 1995; Acka et al., 2014). O produto da técnica de inversão, isto é, dos dados submetidos a uma análise quantitativa, é entendido como imageamento elétrico bidimensional (Asry et al., 2012; Brillante et al., 2015).

\section{3 - MATERIAL E MÉTODOS}

\section{1 - Área de Estudo}

O trabalho foi desenvolvido num trecho da vertente do córrego Capetinga, cuja bacia hidrográfica esta localizada, em sua maior parte, na Fazenda Água Limpa (FAL), localizada na porção sudoeste do Distrito Federal (Figura 1). A FAL é uma fazenda experimental, administrada pela Universidade de Brasília (UnB), com área aproximada de $43 \mathrm{~km}^{2}$, destinada à preservação (23 $\left.\mathrm{km}^{2}\right)$, conservação $\left(8 \mathrm{~km}^{2}\right)$ e produção agropecuária $\left(12 \mathrm{~km}^{2}\right)$. A fazenda integra a Área de Proteção Ambiental (APA) da bacia hidrográfica do Gama e Cabeça-de-Veado, tributária do Lago Paranoá que, por sua vez, pertence à região hidrográfica do Paraná (UnB, 2009). Além disso, uma porção da 
Fazenda é constituída pela Área de Relevante Interesse Ecológico (ARIE) Capetinga/Taquara, também denominada Estação Ecológica da Universidade de Brasília, constituída pelas bacias hidrográficas dos córregos Taquara e Capetinga (UnB, 2009).

Considerando o sistema climático definido por Koppen, a bacia do córrego Capetinga possui clima tropical do tipo Cwa, com características de clima tropical de altitude (CODEPLAN, 1984). localiza-se numa região com altitude media de 1100 m, com amplitude de variação de 160 m, sendo as cotas topográficas máxima e mínima equivalentes a 1210 e 1050 m, respectivamente. Com relação aos aspectos pedológicos, por sua vez, a bacia apresenta Latossolos Vermelho e VermelhoAmarelo, além de Cambissolo Háplico e solos Hidromórficos (Embrapa, 1978; Macedo, 1996; Reato et al., 2004).
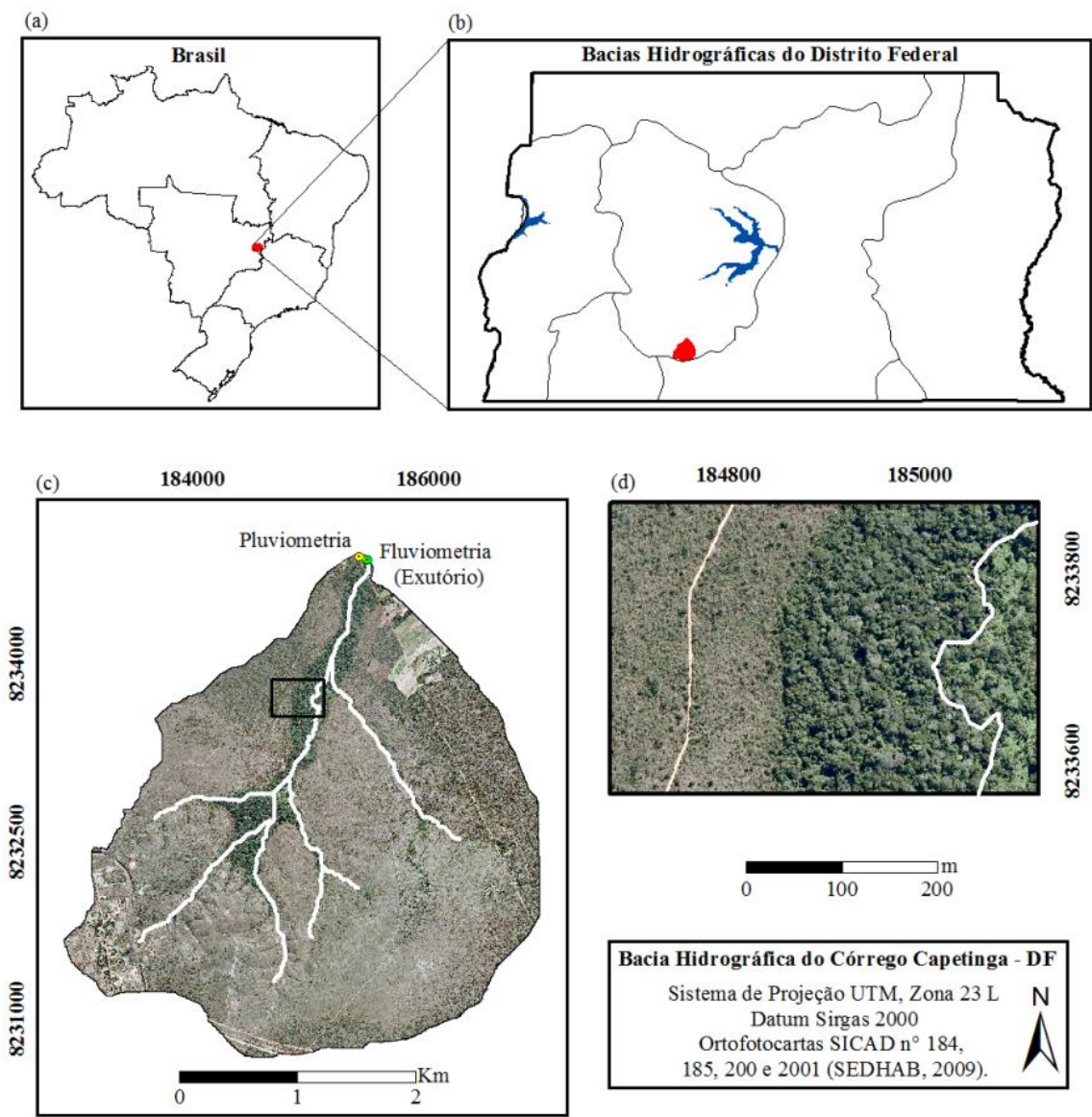

Figura 1 - Localização da área de estudo. b) Destaque para o posicionamento da bacia hidrográfica do córrego Capetinga no Distrito Federal. c) Bacia do córrego Capetinga em escala de 1:45000, delimitada de modo a considerar a área de influência até a Estação Fluviométrica FAL - UnB (exutório). d) Visualização detalhada da vertente em estudo, com escala de 1:5000. O Córrego Capetinga foi representado pelo traçado branco para contraste.

$\mathrm{Na}$ bacia do córrego Capetinga foram identificadas formações geológicas das unidades Ardósia (MNPpr4) e Metarritmito Arenoso (MNPpq3), ambas pertencentes ao grupo Paranoá (Moraes e Campos, 2008). No que diz respeito às características hidrogeológicas, por sua vez, podem ser identificados os domínios aquíferos poroso e fraturado, conforme Lousada e Campos 
(2005). Neste estudo, a abordagem das águas subterrâneas será restrita ao domínio aquífero poroso que apresenta grande importância, principalmente, pelo fato da espessura da camada saturada e da condutividade hidráulica $(K)$ favorecerem o escoamento de base nos períodos de estiagem e ainda por representarem uma interface entre a zona não saturada e os aquíferos mais profundos, inclusive aqueles do domínio fraturado (Campos e Freitas-Silva 1998, Bugan et al., 2010).

\section{2 - Levantamento Geofísico}

Dados de resistividade elétrica foram adquiridos considerando o arranjo experimento instalado na vertente do córrego Capetinga (Figura 2). O monitoramento geofísico foi realizado em três linhas $(A, B$ e $C$ ) paralelas ao córrego Capetinga, com $200 \mathrm{~m}$ de comprimento cada, espaçadas 100 metros entre si. A instalação do experimento ocorreu entre janeiro e agosto de 2015. Inicialmente foi realizado o levantamento do traçado do córrego Capetinga junto à vertente em estudo para permitir correta localização do experimento, sendo utilizado um GPS modelo Etrex da Garmin, com precisão de $5 \mathrm{~m}$. Em seguida, três trilhas, com $200 \mathrm{~m}$ de comprimento cada, foram abertas para permitir a disposição dos eletrodos e fios utilizados no levantamento geofísico.

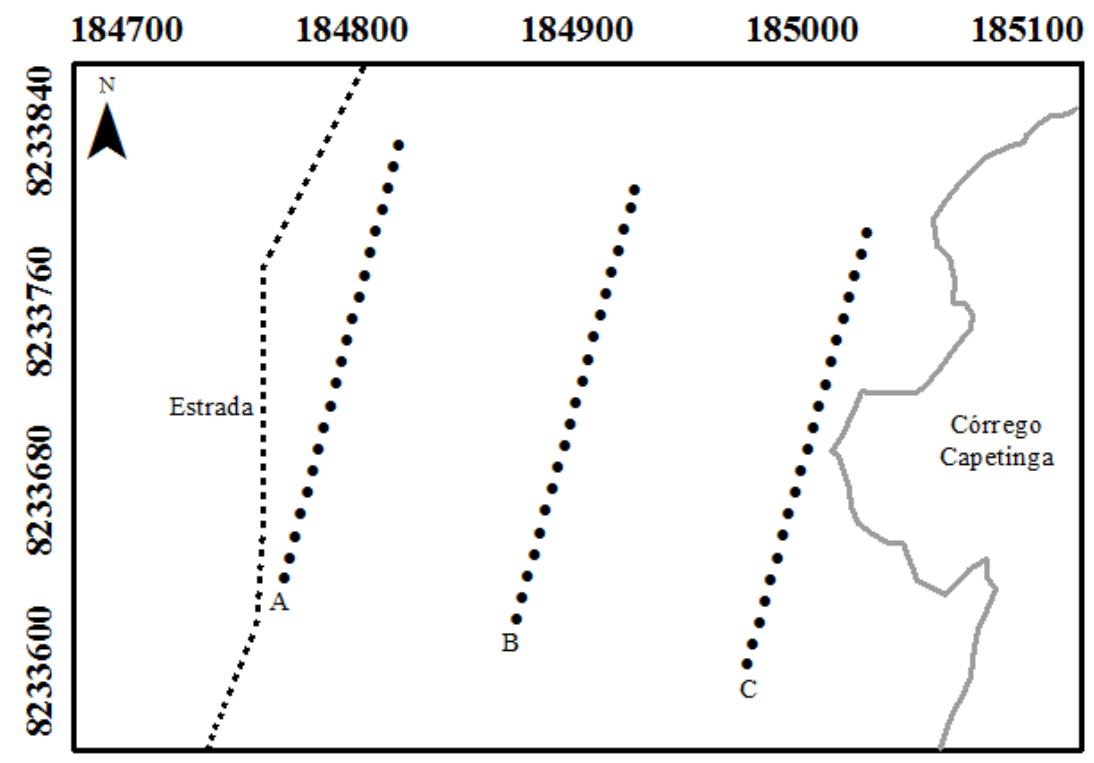

Figura 2 - Ilustração esquemática do desenho experimental adotado na vertente do Córrego Capetinga, com três linhas de monitoramento totalizando $200 \mathrm{~m}$ cada. As letras de " $A$ " a " $C$ " designam as seções paralelas ao córrego, com eletrodos espaçados $10 \mathrm{~m}$ entre si, sendo a linha " $A$ " mais distante do corpo hídrico superficial.

Para obtenção do parâmetro resistividade aparente foi empregado o método elétrico de corrente contínua, por meio da técnica de caminhamento elétrico ou perfilagem elétrica horizontal, que possibilitou o conhecimento da variação horizontal da resistividade a partir de pontos não fixos na superfície do terreno, com uma ou mais profundidades constantes (Braga, 2007). Com a técnica selecionada realizou-se o imageamento elétrico do solo em seções bidimensionais. Para 
desenvolvimento do experimento foi adotado o arranjo $\alpha$-Wenner, identificado genericamente como arranjo de Wenner, com espaçamento equidistante dos eletrodos em cada nível de investigação.

Foi adotado espaçamento entre os quatros eletrodos equivalente a 10 metros no primeiro nível de investigação, 20 metros para o segundo, e assim consecutivamente até o sexto nível, com 60 metros de espaçamento (Figura 3). Considerando o espaçamento máximo de 60 metros em todas as linhas foi obtida uma profundidade de investigação teórica de 30 metros. Placas de conexão foram elaboradas a partir de placas de polietileno (tábua de corte de cozinha), permitindo entre os cabos, que foram fixados aos parafusos e devidamente isolados na parte inferior da tábua, e o equipamento utilizado na aquisição dos dados geofísicos no período de agosto de 2015 a fevereiro de 2016, totalizando nove semanas de monitoramento. O resistivímetro Geopulse foi utilização na aquisição dos valores de resistência, posteriormente convertidos a resistividade do solo (Figura 4).

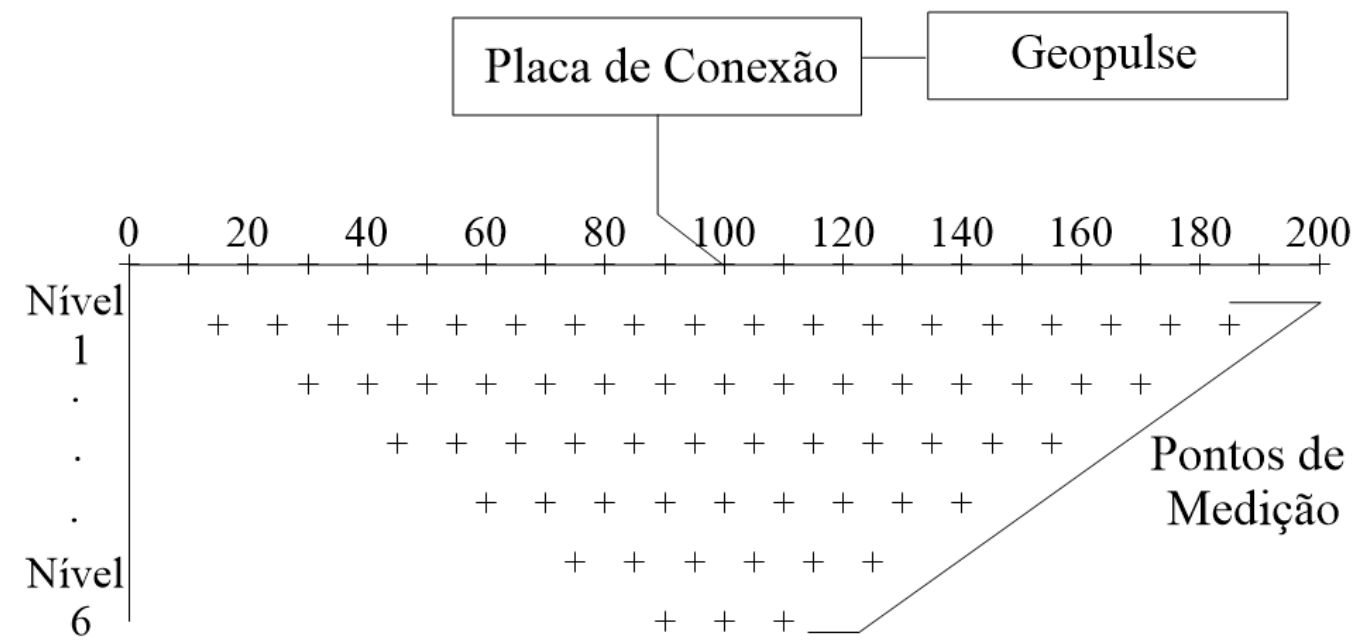

Figura 3. Representação esquemática da aquisição de dados nas seções, com espaçamento de 10 metros entre os eletrodos a partir do nível 1, totalizando 76 pontos de medição em cada seção.

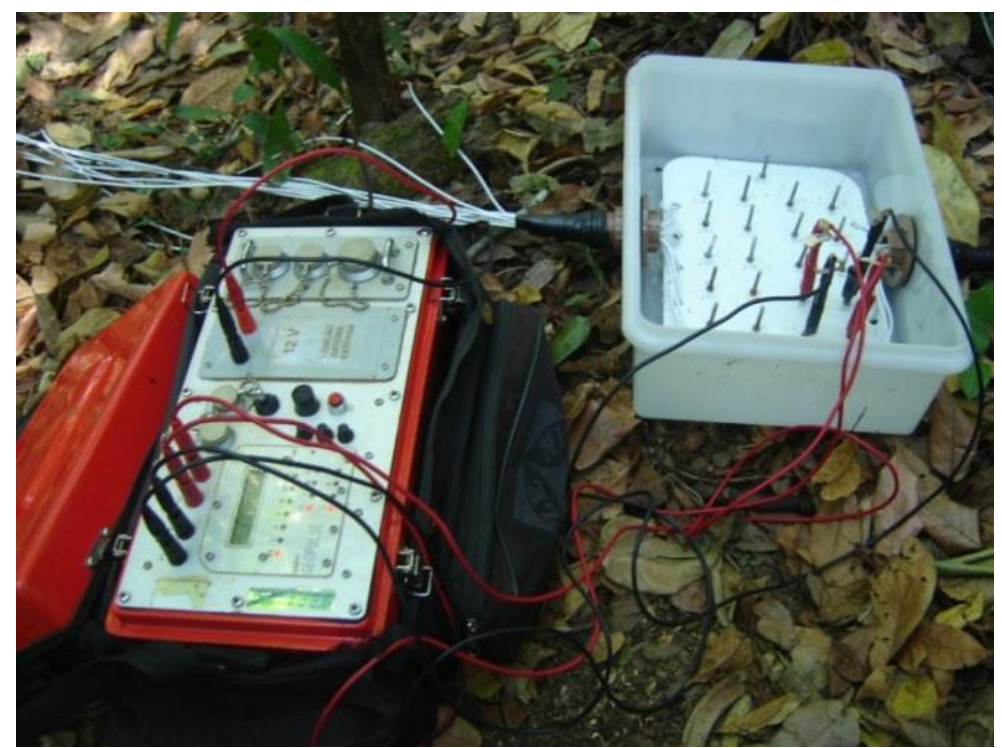

Figura 4. Aquisição dos dados de campo, com destaque para o resistivímetro Geopulse interligado à placa de conexão dos eletrodos. 


\section{3 - Tratamento de Dados}

A etapa de tratamento de dados foi iniciada com a filtragem e substituição manual dos valores discrepantes pela media dos vizinhos mais próximos para cada nível de investigação. Os dados de resistividade aparente foram plotados no formato de perfil utilizando a versão demonstrativa do programa RES2DINV (versão 4.00; Geotomo Software; Loke, 2001), destacando pontos discrepantes em relação aos demais e permitindo sua remoção do conjunto de dados. Após a remoção dos dados com ruído, os valores de resistividade elétrica aparente foram invertidos por meio da técnica de otimização não linear de mínimos quadrados, seguida da modelagem direta pelo método de diferenças finitas, utilizando o programa RES2DINV, que permite a elaboração de um modelo bidimensional para espacialização dos valores de resistividade no subsolo (Griffiths e Barker, 1993).

A variação temporal dos dados foi quantificada, em porcentagem, a partir da diferença entre os valores de resistividade elétrica obtidos para cada intervalo de tempo $t_{1}\left(\rho_{1}\right)$ e aqueles obtidos no tempo inicial $t_{0}\left(\rho_{0}\right)$ (Equação 5). Desse modo, as seções geoelétricas de cada linha foram comparadas àquelas obtidas no mês de agosto de 2015. Essa metodologia foi adotada com base no trabalho realizado por Bellmunt et al. (2012).

$$
\% \Delta_{\rho}=\left(\frac{\rho_{1}-\rho_{0}}{\rho_{0}}\right) \times 100
$$

\section{4 - RESULTADOS E DISCUSSÃO}

O imageamento elétrico do solo foi apresentado em seções bidimensionais, com os respectivos erros médios absolutos (\%), como observado na Figura 5, que apresenta a variação da resistividade elétrica em subsuperfície com relação às profundidades investigadas $(5,10,15,21,28$ e $35 \mathrm{~m}$ a partir da superfície do solo) em função das datas de realização dos levantamentos . É importante considerar que o primeiro nível observado está posicionando 5 metros abaixo da superfície do solo. A porção de solo contida entre 0 e $5 \mathrm{~m}$ é entendida como a extensão vertical dos dados apresentados na profundidade de investigação de $5 \mathrm{~m}$. Por apresentaram distribuição não normal, como medida de estatistica descritiva dos valores de resistividade foi adotada a mediana. Os valores de resistividade nas três linhas permaneceram em torno de $4000 \Omega . m$, correspondendo a um valor típico de solos arenosos (Asawa, 2008). A linha $B$ apresentou valores mais resistivos em 
comparação às demais (4004 $\Omega . m)$, seguida pela seção $A(3728 \Omega . m)$. A linha $C$, por sua vez, apresentou mediana igual a $3577 \Omega . m$.

Como afirmam Solberg et al. (2012), os dados mais confiáveis estão posicionado no centro do perfil geoelétrico devido à maior resolução obtida nesse ponto por meio do método de caminhamento elétrico com arranjo de Wenner. Desse modo, a observação da porção central dos perfis possibilita a identificação de camadas horizontalmente estendidas em subsuperficie, indicando uniformidade dos valores de resistividade ao longo da camada, e a ocorrência de anomalias de baixa resistividade (abaixo de $3000 \Omega$.m) nas linhas $B$ e $C$. Esses comportamento foi recorrente ao longo das semanas de investigação. Pelo contrário, na linha $A$, a observação de comportamento estratificado das camadas geoelétricas tende a ser isolado considerando toda a seção.

Chukwauma et al. (2015), ao estudarem a vulnerabilidade de aquíferos sedimentares em solos arenosos na Nigéria, identificaram o nível da água subterrânea, utilizando o mesmo método empregado neste estudo, por associação com profundidades do solo cuja resistividade elétrica foi menor ou igual a $3800 \Omega . m$. Nesse estudo, a partir da observação do comportamento do solo ao longo das seções e da literatura existente, o nível freático foi atribuído a valores de resistividade inferiores a 3000 S.m. No perfil $A$ os valores de resistividade permaneceram elevados em todo o domínio do modelo, não havendo indicativo do nível da água subterrânea, considerando-se profundidade máxima de investigação de $30 \mathrm{~m}$. Em contraponto, para as linhas $B$ e $C$, localizadas mais próximas ao córrego, é possivel observar a extensão lateral de camadas cuja resistividade foi associada ao comportamento de solos saturados.

A variação temporal da resistividade elétrica foi apresentada na Figura 6, como a porcentagem de variação, numa escala de -40 a 140, sendo que a variação negativa indica redução da resistividade em relação ao período inicial de monitoramento (19 de agosto de 2016). A observação da Figura 6 permite identificar o aumento da resistividade nas três seções geoelétricas. Esse comportamento é perceptível especialmente nas seções $B$ e $C$, com aumento gradual nos valores de resistividade a partir da camada superficial. Com isso, pode inferir que a redução da umidade do solo em função do período de estiagem refletiu no aumento dos valores de resistividade elétrica. As seções obtidas a partir de 10 de novembro de 2015, sob influência dos primeiros eventos chuvosos, indicam redução da resistividade elétrica em função, provavelmente, do aumento no teor de água no solo (Figura 7). Desse modo, com ínicio do período chuvoso o que se observou foi a redução da resistividade a partir de $5 \mathrm{~m}$ de profundidade em contraponto aos valores elevados nas camadas mais profundas, com indicativo da redução do nível da água subterrânea. 
Linha A
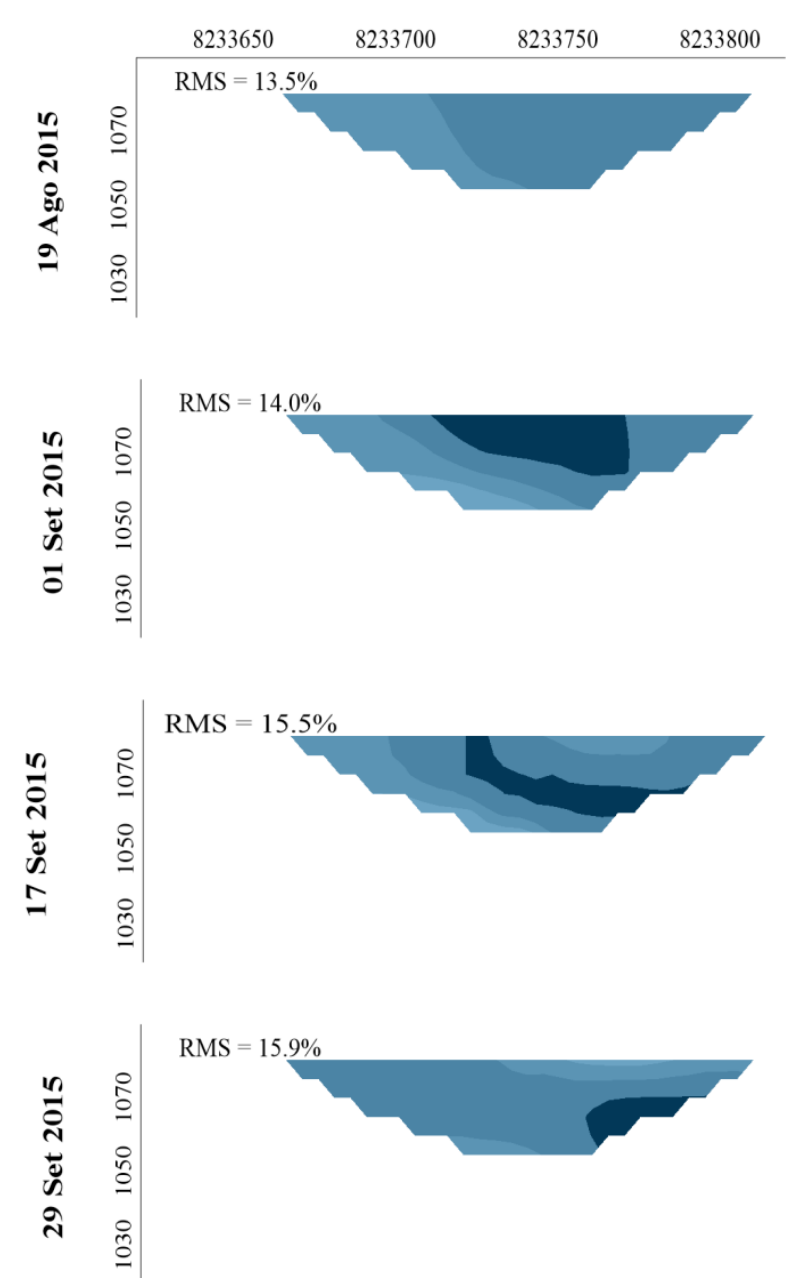

Linha B

$8233650 \quad 8233700$

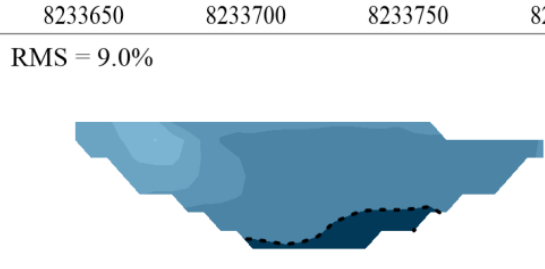

RMS $=6.9 \%$

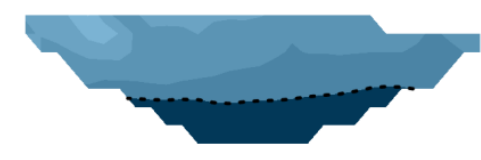

RMS $=6.0 \%$

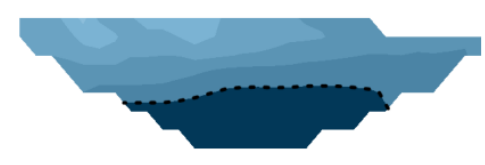

RMS $=7.2 \%$

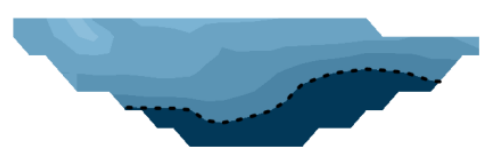

Linha C

$\begin{array}{ll}8233650 & 8233700\end{array} 8233750$ 8233800 $\mathrm{RMS}=5.2 \%$

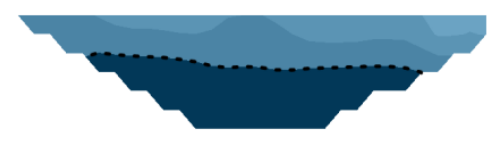

RMS $=8.4 \%$

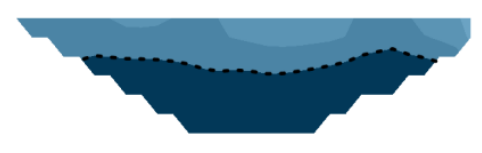

RMS $=4.7 \%$

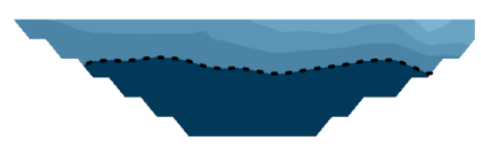

RMS $=7.9 \%$

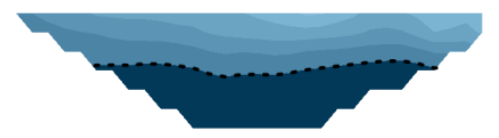



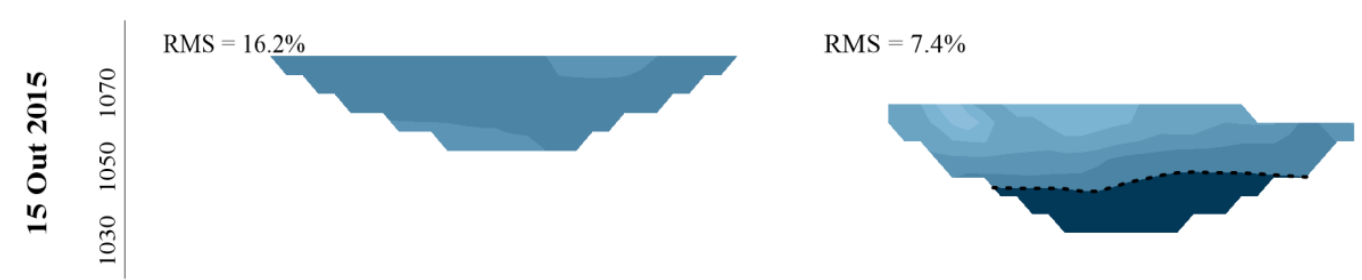

RMS $=6.3 \%$

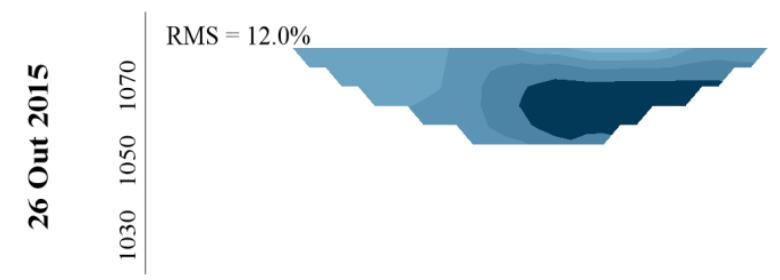

RMS $=5.9 \%$

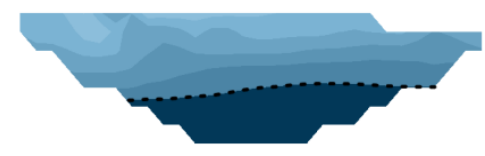

$\mathrm{RMS}=8.8 \%$

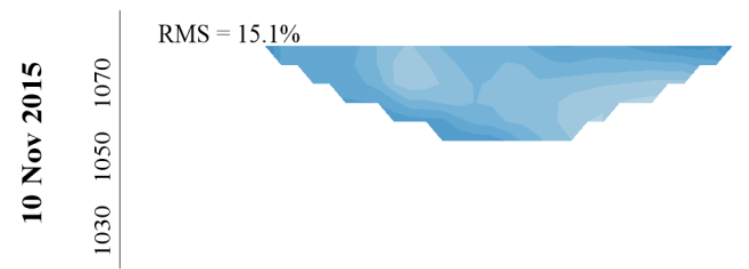

RMS $=5.4 \%$

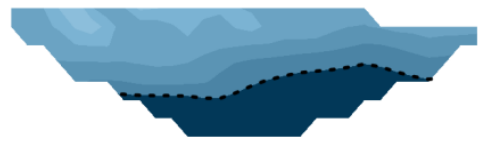

RMS $=6.6 \%$

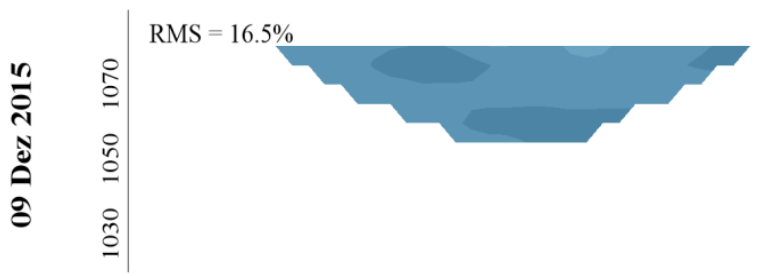

$\mathrm{RMS}=4.0 \%$
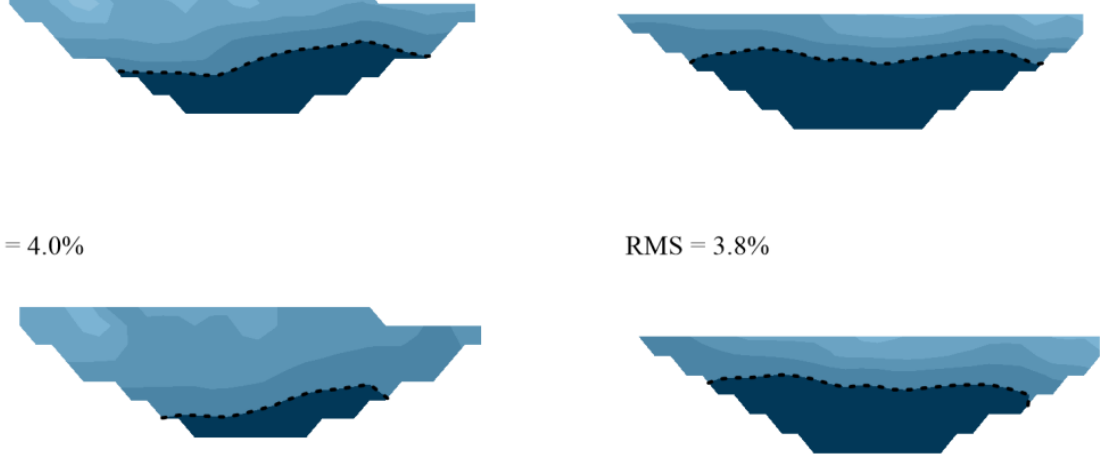

RMS $=3.8 \%$

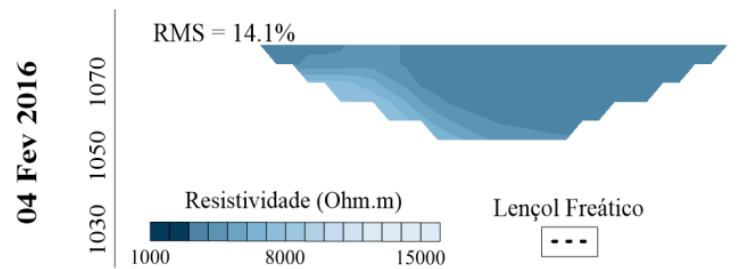

RMS $=8.2 \%$

RMS $=4.2 \%$
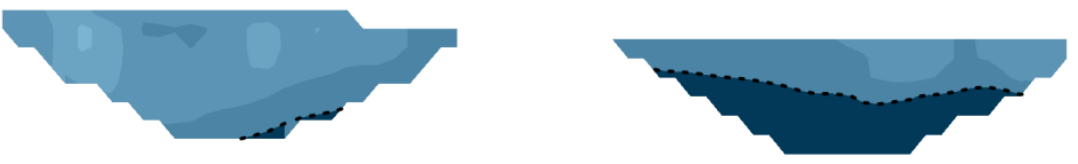

Figura 5. Imageamento da resistividade elétrica do solo em seções bidimensionais, com valores de altitude no eixo $y$ e latitude no eixo $x$. 
Linha A
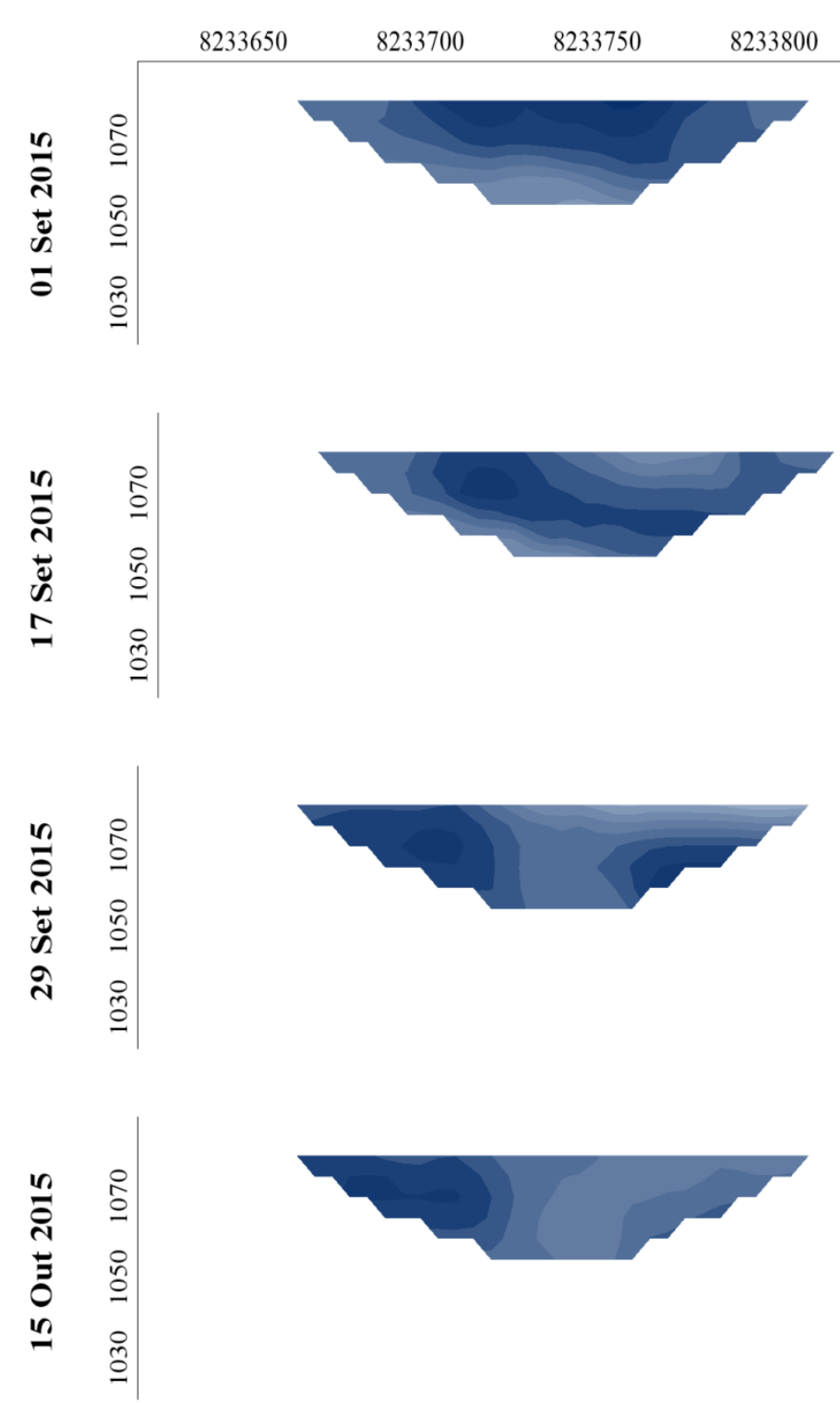

Linha B
8233650
8233700
8233750

8233800

8233650

Linha C
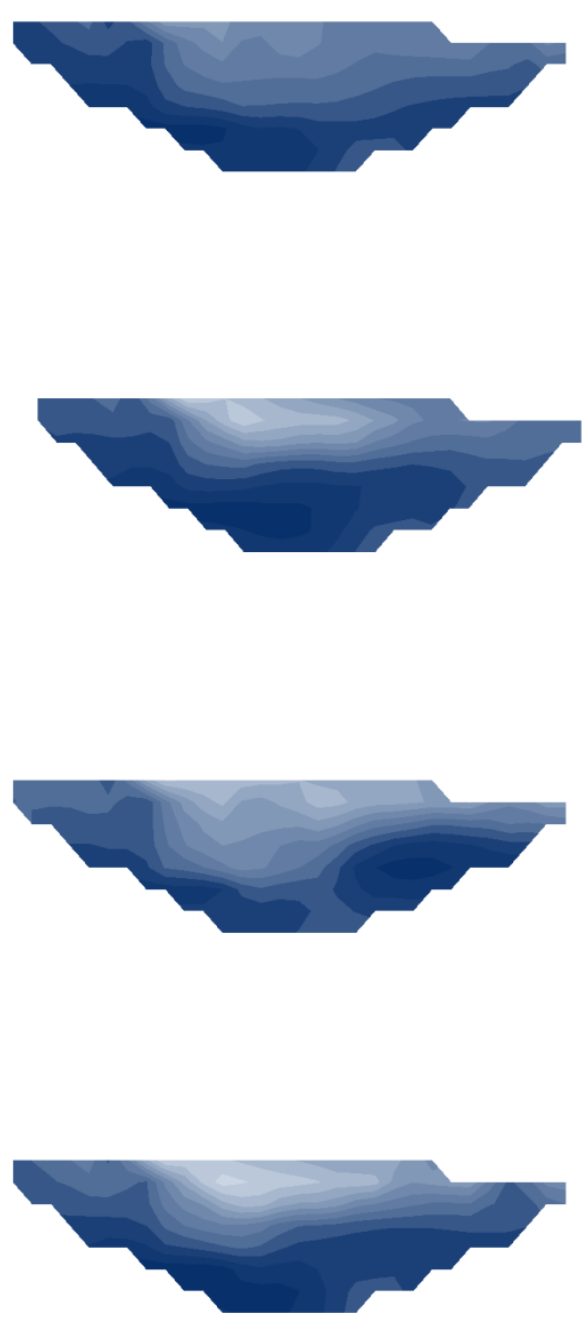
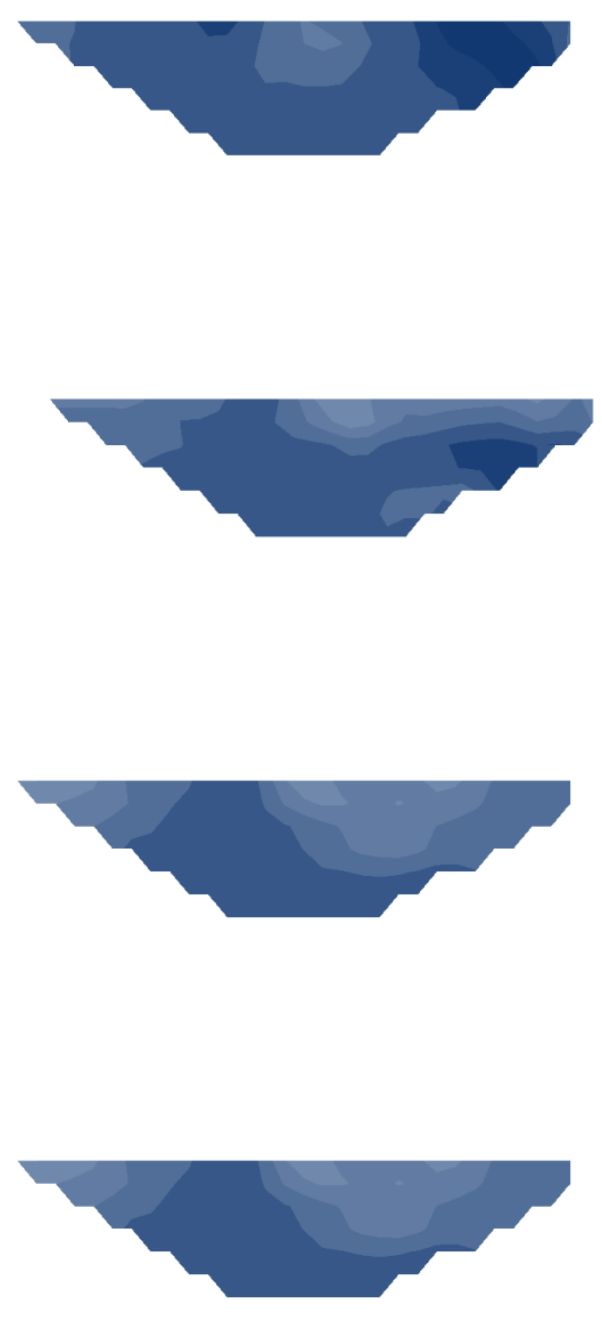


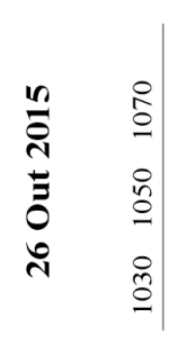

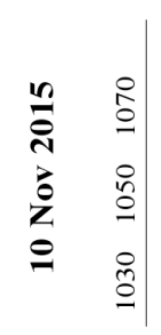

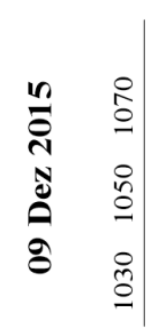
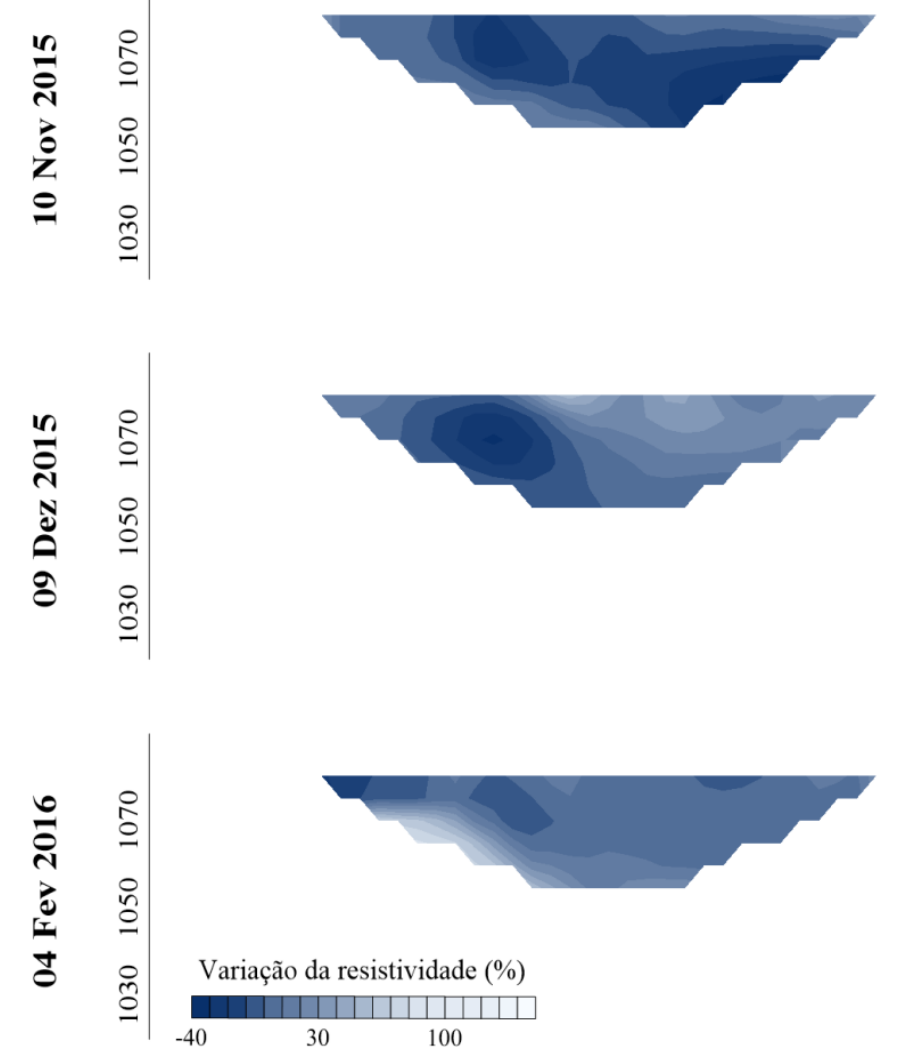
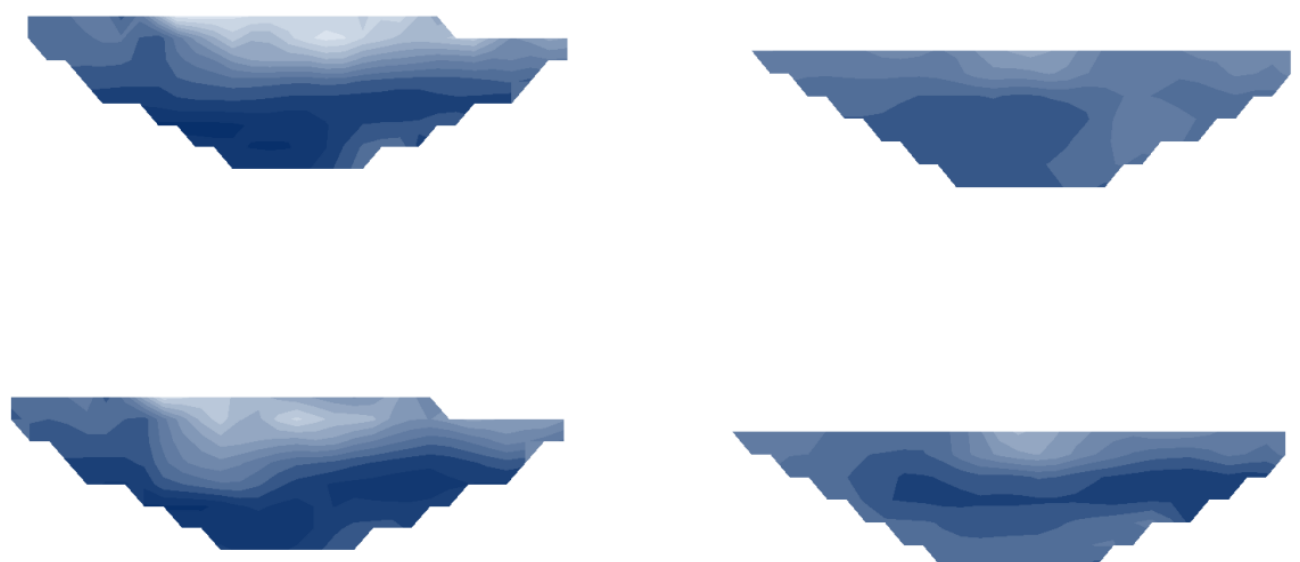

Figura 6. Percentual de variação da resistividade elétrica do solo em relação a agosto de 2015 (início do estudo). 


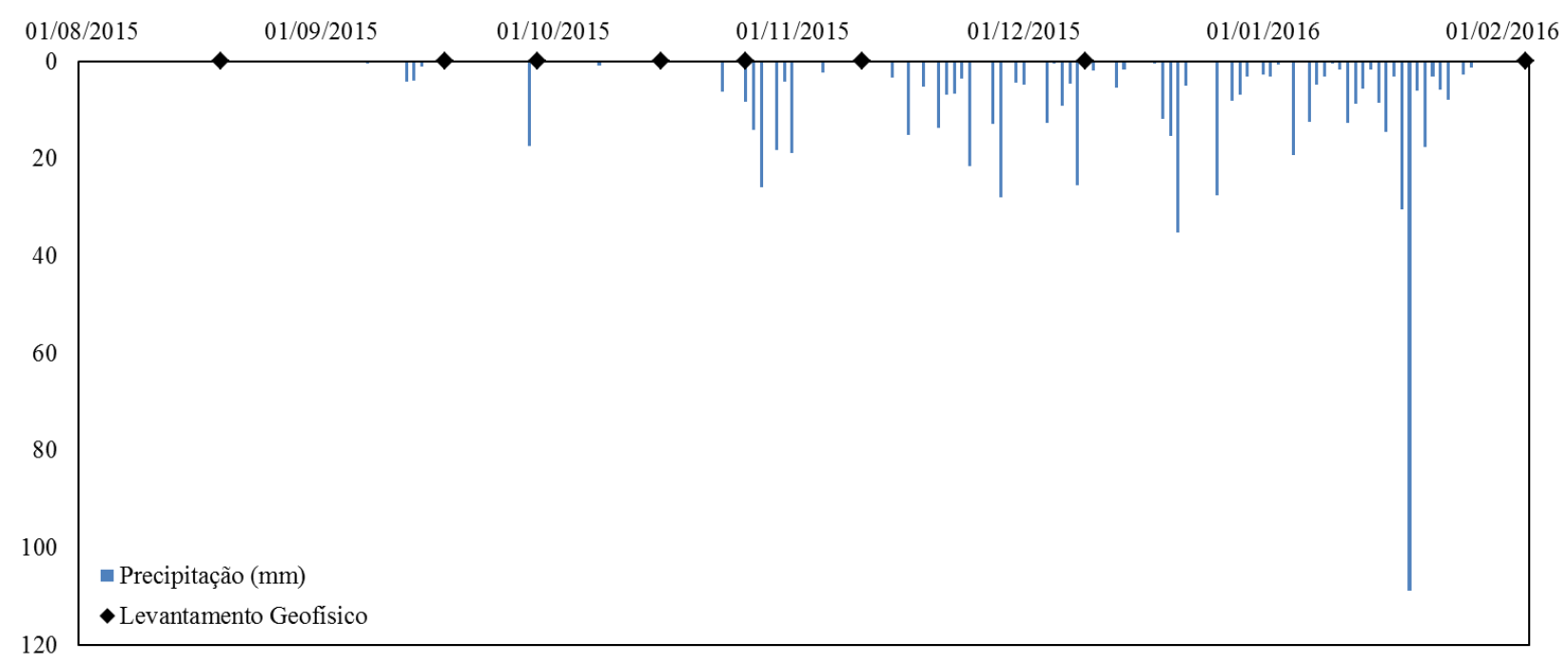

Figura 7. Precipitação diária (mm/d) ao longo do período de estudo (agosto de 2015 a fevereiro de 2016), com indicação da ocorrência dos levantamentos geofísicos.

\section{6 - CONCLUSÃO}

O método elétrico de corrente contínua mostrou-se adequado ao objetivo proposto, sendo possível identificar padrão de distribuição da resistividade elétrica do solo entre os perfis, tanto nas profundidades investigadas quanto entre as linhas dispostas na vertente selecionada. Os valores de resistividade elétrica inferiores a $3000 \Omega . m$, considerando informações bibliográficas e a observação do comportamento em campo, foram considerados indicativos do nível da água subterrânea, especialmente nas seções $B$ e $C$. Considerando a umidade e a resistividade variáveis inversamente proporcionais, a análise temporal permitiu inferir um padrão de redução da umidade por meio do aumento gradual da resistividade na camada superficial do solo ao longo do período de estiagem. As seções realizadas na estação chuvosa, por sua vez, demonstraram redução da resistividade, provavelmente em função do aumento no teor de água no solo. Desse modo, informações qualitativas do comportamento da água no solo em zonas ripárias foram obtidas, sendo necessária a verificação desses resultados por meio de correlação com medidas diretas de umidade do solo e do nível do lençol freático no domínio aquífero poroso.

\section{REFERÊNCIAS}

Andersen, T.R.; Poulsen, S.E.; Christensen, S.; Jorgensen, F. (2013). A synthetic study of geophysics-based modelling of groundwater flow in catchments with a buried valley. Hydrogeology Journal, v. 21, p. $491-503$.

Asawa, G.L. (2008). Irrigation and Water Resources Engineering. New Delhi: New Age International Limited Publishers. $623 \mathrm{p}$.

Asry, Z.; Samsudin, A.R.; Yaacob, W.Z.; Yaakub, J. (2012). Groundwater Exploration Using 2-D Geoelectrical Resistivity Imaging Technique at Sungai. Udang, Melaka. Journal of Earth Science and Engineering, v. 2, p. 624-630. 
Awan, U.S.K.; Tischbein, B.; Martius, C. (2015). Simulating groundwater dynamics using feflow$3 \mathrm{~d}$ groundwater model under complex irrigation and drainage network of dryland ecosystems of central Asia. Irrigation and Drainage, v. 64, p. 283.

Barker, R.D. (1989). Depht of investigation of collinear symmetrical four-electrode arrays. Geophysics, v. 54, n. 8, p. 1031-1037

Besson, A.; Cousin, I.; Bourennane, H.; Nicoullaud, B.; Pasquier, C.; Richard, G.; Dorigny, A.; King, D. (2010). The spatial and temporal organization of soil waterat the field scale as described by electrical resistivity measurements. European Journal of Soil Science, February, v. 61, p. 120-132.

Blumstock, M.; Tetzlaff, D.; Malcolm, I.A.; Nuetzmann, G.; Soulsby, C. (2015). Baseflow dynamics: Multi-tracer surveys to assess variable groundwater contributions to montane streams under low flows. Journal of Hydrology, v. 527, p. 1021-1033.

Braga, A. C. O. (2007). Métodos Geofísicos Aplicados: Módulo Hidrogeologia. Rio Claro: Universidade Estadual Paulista. 79 p.

Brillante, L.; Bois, B.; Mathieu, O.; Bichet, V.; Michot, D.; Lèvêque, J. (2014). Monitoring soil volume wetness in heterogeneous soils by electrical resistivity. A field-based pedotransfer function. Journal of Hydrology, v. 516, p. 56-66.

Brutsaert, W. (2005). Hydrology: An introduction. New York: Cambrige University Press. 617 p.

Bugan, R.D.H.; Jovanovic, N.Z.; Clercq, W.P. (2012). The water balance of a seasonal stream in the semi-arid Western Cape (South Africa). Water, v. 38, n. 2. p. 201-212.

Burt, T.P.; Pinay, G.; Matheson, F.E.; Haycock, N.E.; Butturini, A. Clement, J.C.; Danielescu, S.; Dowrick, D.J.; Hefting, M.M.; Hillbricht-Ilkowska, A.; Maitre, V. (2002). Water table fluctuations in the riparian zone: comparative results from a pan-European experiment. Journal of Hydrology, v. 265, p. 129-148.

Carpenter, E.W. (1955). Some notes concerning the Wenner configuration. Geophysical Prospecting, v. 3, p. 338-402.

Castelloé, J.F.; Peterson, T.J.; Halbert, K.; Western, A.W.; Mcdonnell, J.J. (2015). Groundwater surface mapping informs sources of catchment baseflow. Hydrol. Earth Syst. SCI, v. 19, p. $1599-1613$.

Chukwuma E.C.; Orakwe, L.C.; Anizoba, D.C.; Amaefule, D.O.; Odoh, C.C.; Nzediegwu, C. (2015). Geo-electric Groundwater Vulnerability Assessment of Overburden Aquifers atAwka in Anambra State, South-Eastern Nigeria. European J. Biot. Bioscience, v. 3, n.1, p. 29-34.

CODEPLAN. (1984). Atlas do Distrito Federal. Brasília: Secretaria do Governo/Secretaria da educação e Cultura/CODEPLAN. v. 1. 78p.

Detty, J.M.; Mcguire, K.J. (2010). Topographic controls on shallow groundwater dynamics: implications of hydrologic connectivity between hillslopes and riparian zones in a till mantled catchment. Hydrological Processes, v. 24, p. 2222-2236.

Donohue, S.; McCarthy, V.; Rafferty, P.; Orr, A. Flynn, R. (2015). Geophysical and hydrogeological characterisation of the impacts of on-site wastewater treatment discharge to groundwater in a poorly productive bedrock aquifer. Science of the Total Environment, n. 523, p. 109-119.

EMBRAPA. (1978). Levantamento de reconhecimento dos solos do Distrito Federal. Rio de Janeiro: EMBRAPA-SNLCS. 455 p.

Eunice, V.B.; Luiz, J.G.; Leal, L.R.B.; Fenzl, N.; Morales, G.P. (2011). Diagnóstico sobre contaminação das águas subterrâneas na área do parque estadual do Utinga, Belém - PA, pelos métodos elétrico e eletromagnético. Revista Brasileira de Geofísica, Brasil, v. 29, n. 4, p. 753-770.

Feitosa, E.C. (1997). Pesquisa de Água Subterrânea. In: Feitosa, F.A.C.; Manoel-Filho, J. Hidrogeologia: Conceitos e Aplicações. Fortaleza: CPRM, LABHID - UFPE. 412 p. 
Freyberger, J.V.; Radny, D.; Gall, H.E.; Schirmer, M. (2014). Implications of hydrologic connectivity between hillslopes and riparian zones on streamflow composition. Journal of Contaminant Hydrology, v. 169, p. 62-74.

Griffiths, D.H.; Barker, R.D. (1993). Two-dimensional resistivity imaging and modelling in areas of complex geology. Journal of Applied Geophysics, v. 29, p. 211-226.

Jencso, K.G.; McGlynn, B.L.; Gooseff, M.N.; Bencala, K.E.; Wondzell, S.M. (2010). Hillslope hydrologic connectivity controls riparian groundwater turnover: Implications of catchment structure for riparian buffering and stream water sources. Water Resources Research, v. 46, $18 \mathrm{p}$.

Jencso, K.G.; McGlynn, B.L.; Gooseff, M.N.; Bencala, K.E.; Wondzell, S.M. (2010). Hillslope hydrologic connectivity controls riparian groundwater turnover: Implications of catchment structure for riparian buffering and stream water sources. Water Resources Research, v. 46, $18 \mathrm{p}$.

Knight, R.; et al. (2010), Geophysics at the interface: Response of geophysical properties to solidfluid, fluid-fluid, and solid-solid interfaces. Rev. Geophys., v. 48, 30 p.

Koefoed O. (1979). Resistivity Sounding Measurements. Amsterdan: Elsevier. 276 p.

Loke, M.H. (2001). Topographic modelling in electrical imaging inversion. In: $62^{\text {nd }}$, EAGE Conference and Technical Exhibition. Glasgow, Scotland.

Lousada, E.O.; Campos, J.E.G. (2005). Proposta de modelos hidrogeológicos conceituais aplicados aos aqüíferos da região do Distrito Federal. Revista Brasileira de Geociências, Brasil, v. 35, n. 3, p. 407-414.

Lowrance, R. et al. (1984). Riparian Filters in Watersheds Agricultural. BioScience, v. 34, n. 6, p. 374-377.

Macedo, J. (1996). Solos da região do Cerrado. In: alvarez, V. H.; fontes, L. E. F.; fontes, M. P. F.(orgs). O solo nos grandes domínios morfoclimáticos do Brasil e o desenvolvimento sustentado. Viçosa: Universidade Federal de Viçosa. p. 135-156.

Monte-Mor, R.C.A.; Palmier, L.R.; Pinto, E.J.A.; Lima, J.E.S. (2012). Estabilidade Temporal da Distribuição Espacial da Umidade do Solo em uma Bacia Intermitente no Semiárido de Minas Gerais. Revista Brasileira de Recursos Hídricos, v. 17, n.3, p. 101-113.

Moraes, L. L.; Campos, J. E. G. (2008). Hidrogeologia. In: Fonseca, F. O. (Org.). Águas Emendadas. Brasília: Secretaria de Desenvolvimento Urbano e Meio Ambiente. p. 122-131.

Musgrave, H.; Binley, A. (2011). Revealing the temporal dynamics of subsurface temperature in a wetland using time-lapse geophysics. Journal of Hydrology, v. 396, p. 258-266.

Naiman, R.J.; Décamps, H. (1997). The ecology of interfaces: riparian zones. Annu. Rev. Ecol. Syst, n. 28, p. 621-658.

Naiman, R.J.; Décamps, H.; McClain, M.E (2005). Riparian: Ecology, Conservation, and Management of Streamside Communities. UK: Elsevier. 446 p.

Nascimento, C.T.C.; Varella, R.F.; Pires, A.C.B.; Santos, R.V. (2001). Valores de Resistividade Elétrica em um Latossolo do Distrito Federal. In: Congresso Internacional da Sociedade Brasileira de Geofísica, 7. Anais... Bahia: Sociedade Brasileira de Geofísica.

Nascimento, C.T.C.; Pires, A.C.B.; Moraes, R.A.V. (2004). Reconhecimento de solos por meio de resistividade elétrica e radiação gama. Revista Brasileira de Geociências, Brasil, v. 34, n. 3, p. 383-392.

Neves, A.V.B.; Luiz, J.G. (2015). Estimativa da velocidade de fluxo subterrâneo por imageamento elétrico. Águas Subterrâneas, v. 29, n. 1, p. 104-115.

Orellana, E. (1972). Prospeccion Geoelectrica en Corriente Continua. Madrid, Paraninfo. 523p.

Poulsen, J.R.; Sebok, E.; Duque, C.; Tetzlaff, D.; Engesgaard, P.K. (2015). Detecting groundwater discharge dynamics from point-to-catchment scale in a lowland stream: combining hydraulic and tracer methods. Hydrol. Earth Syst. Sci., v. 19, p. 1871-1886.

Reatto, A.; Martins, E.S.; Farias, M.F.R.; Silva, A.V.; Carvalho, O.A.J. (2004). Mapa pedológico digital - SIG atualizado do DF escala 1:100.000 e uma síntese do texto explicativo. Planaltina: Embrapa Cerrados. 31 p. 
Ren, Z.; Tang, J. (2014). A goal-oriented adaptive finite-element approach for multi-electrode resistivity system. Geophys. J. Int., v. 199, p. 136-145.

Solberg, I.L.; Hansen, L.; Ronning, J.S.; Haugen, E.D.; Dalsegg, E.; Tonnesen, J.F. (2012). Combined geophysical and geotechnical approach to ground investigations and hazard zonation of a quick clay area, mid Norway. Bull Eng Geol Environ, v. 71, p. 119-133.

Telford, W. M.; Geldart, L. P.; Sheriff, R.E. (1990). Applied Geophysics. Cambridge University Press, Cambridge. $771 \mathrm{p}$

UnB - Universidade de Brasília. (2009). Histórico da Fazenda Água Limpa. Disponível em: < http://www.fal.unb.br/index.php?option=com_content\&view=article\&id=51:historico\&catid $=35$ :fazenda-agua-limpa\&Itemid=61>. Acesso em: 28 mai. 2015 .

Wienhofer, J.; Germer, K.; Lindenmaier, F.; Farber, A.; Zehe, E. (2009). Applied tracers for the observation of subsurface stormflow at the hillslope scale. Hydrol. Earth Syst. Sci., v. 13, p. $1145-1161$.

Wunderlich, T.; Wilken, D.; Andersen, J.; Rabbel, W.; Zori, D.; Kalmring, S.; Byock, J. (2015). On the Ability of Geophysical Methods to Image Medieval Turf Buildings in Iceland. Archaeol. Prospect.

Yeboah-Forson, A.; Whitman, D. (2014). Electrical Resistivity Characterization of Anisotropy in the Biscayne Aquifer. Groundwater, v. 52, n. 5, p. 728-736.

Zarroca, M; Linares, R.; Rodellas, V.; Garcia-Orellana, J.; Roqué, C.; Bach, J.; Masqué, P. (2014). Delineating coastal groundwater discharge processes in a wetland area by means of electrical resistivity imaging, 224Ra and 222Rn. Hydrological Processes, v. 28, p. $2382-$ 2395.

\section{AGRADECIMENTOS}

À Fazenda Água Lima (FAL) pela autorização para desenvolvimento da fase experimental deste estudo. Aos funcionários da FAL/UnB que auxiliaram nos trabalhos em campo. Ao Laboratório de Geociências/UnB, por fornecer o equipamento necessário para levantamento de dados geofísicos. A Fundação de Amparo à Pesquisa do Distrito Federal $(F A P-D F)$, pelo suporte financeiro para aquisição dos materiais necessários à instalação do experimento em campo. Ao Conselho Nacional de Desenvolvimento Científico e Tecnológico $(C N P q)$ e a Coordenação de Aperfeiçoamento de Pessoal de Nível Superior (CAPES), pelas bolsas de estudos concedidas. 